\title{
Is Rate of Stock Returns a Leading Indicator of Output Growth? In the Case of Four East Asian Countries
}

\author{
Pei-Fen Chen ${ }^{1}$, Chien-Chiang Lee ${ }^{2}$, and Swee Yoong Wong ${ }^{3}$ \\ ${ }^{1}$ Department of International Business and Trade, Shu-Te University. \\ ${ }^{2}$ Department of Applied Economics, National Chung-Hsing University \\ ${ }^{3}$ Department of International Trade, Shih Chien University, Kaohsiung Campus
}

\begin{abstract}
The link between stock returns and economic growth has been an important research topic in the financial economic literature. The purpose of this study is to employ a threshold vector autoregressive (TVAR) approach in order to investigate the non-linear relationship between stock returns and output growth in the four East Asian countries: Taiwan, Japan, Korea, and Malaysia. The causality between the two under different stock returns regimes are also examined in this study. The empirical findings of this modest study indicate that there is an asymmetric relationship between stock returns and industrial production growth in the four East Asian countries. Finally, the findings from the generalized impulse response function of the VAR model reveal that each country's stock market disturbance has a greater impulse effect on output growth under bad news regime than under good news regime.
\end{abstract}

Keywords: Threshold Vector Autoregressive, Stock Returns, Industrial Production Growth Rate, Causality, Generalized Impulse Response Function

\section{Introduction}

There has been a substantial theoretical work on the link between stock returns and economic growth. Morck et al. (1990) review five existing theoretical links between the two variables, which arguably encompasses most of the main theories that have been put forward in this literature. In addition, the study also provides an excellent survey on most of the debate on the causal direction of the underlying relationship. Mauro (2003) suggests that through the wealth channel, the stock price developments can have a major impact on consumption pattern. Levine and Zervos (1996) conclude that the stock market contributes to a country's economic growth by providing liquid capital, risk management to investors, and information on the movements of economic fundamentals.

On the other hand, several theoretical studies have provided conflicting predictions about the returns-growth association. Bhide (1993) indicates that the volatility of stock market may reduce the ability of the public to supervise on a company's investment efficiency. In addition, the public may increase investment returns by speculating in the stock market; thus, the stock market development may be unfavorable to the economic growth. Obstfeld (1994) indicates that high financial market liquidity may increase investment returns and thus decrease saving rate due to substitution effect and income effect, which is unfavorable to the economic growth. Mauro (1995) finds that when the investment portfolio is taken into account, the development of stock market will decrease the public's precautionary saving, which is also detrimental to the economic growth.

There is a substantial empirical work on the link between the stock returns and output growth. An incomplete list of the studies includes: Fama (1981, 1990), Wahlroos and Berglund (1986), Mullins and Wadhwani (1989), Schwert (1990), Canova and Nicolo (1995), Choi et al. (1999), Doong (2001), and Mauro (2003). Each has found that stock returns and various macroeconomic factors are, to varying degrees, correlated, using either U.S. or other international data. However, some studies provide evidence to the contrary including: Barro (1990), Stock and Watson (1990, 1998), Hu (1993), and Binswanger (2000). The causality relationship between stock returns and economic growth is also investigated in numerous empirical studies. Fama (1990), Schwert (1990), Canova and Nicolo (1995), Doong (2001), and Mauro (2003) conclude that an increase in stock market returns is an indication of an increase in industrial production growth rates.

Extensive empirical studies on the returns growth association have employed linear model methodology and concentrated mainly on three different directions, namely, by investigating (1) the channel through which the stock returns affect the economic growth, (2) the factors that influence the relationship between stock returns and output growth, and (3) the causality between the two. However, more recent findings in the business cycle literature have indicated that many macro time series can be 
characterized by low-frequency, high-amplitude shocks. Because of the existence of these shocks, many macroeconomic time series display systematic asymmetric behavior over various phases of the business cycle. As a result, a linear dynamic model of stock market returns may produce a misleading specification of market performance. This suggests a need to develop a nonlinear model since any member of the wide class of standard linear models cannot represent the asymmetric nature of the business cycle adequately. Consequently, in recent years, there has been a growing interest in the application of nonlinear models for characterizing the cyclical time-series relationship between stock returns and output growth. An incomplete list of the nonlinear studies includes: Tamin (1988), Sichel (1993), Dolian and Louton (1995), Domian and Louton (1997), Filer et al. (1999), and Sarantis (2001).

This study contributes to the existing literature in the following ways: (a) it improves upon past linear econometric methods by the use of vector autoregressive (VAR) and TVAR methodology to examine the correlation between stock returns and output growth and thereby permits us to shed additional evidence on the nonlinear relationship between the two, (b) a TVAR is a relatively simple and intuitive way to capture nonlinearity such as regime switching, and asymmetry implied by the theoretical models of stock returns and macroeconomic activity. Moreover, a TVAR allows stock returns regimes to switch, as a result of shocks, to other variables besides stock returns, so that stock returns regimes are themselves endogenous; thus, the threshold variable(s) in this study is determined by the model endogenously, (c) although previous empirical work on the relationship between stock returns and output growth has been concentrated on advanced countries and, to a less extent, on other developing countries, this relationship remains surprisingly unexplored in the case of East Asia countries despite the growing economic integration among these countries and their importance to the world economy. Considering this relative lack of regional research, this study therefore investigates the possible empirical association between stock returns and output growth in Taiwan, Japan, Korea, and Malaysia, and (d) the causality relationship between stock returns and output growth is examined in the context of VAR methodology. In addition, the impulse response function of the VAR methodology allows us to investigate the impact of the stock market disturbances on economic growth under different stock returns regimes.

\section{Data Description and Stationary Test}

In order to explore the empirical relationship between stock returns and economic growth in
Taiwan, Japan, Korea, and Malaysia, monthly data for real stock price index and industrial production are taken from the AREMOS database of the Ministry of Education and the International Monetary Fund's International Financial Statistics. Since there are no monthly data for GDP available for the above countries, the industrial production growth rate $\left(G P_{t}\right)$ is served as a measure of GDP growth. This method is often used in many of the previous studies. Data on the real stock returns are obtained by transforming the raw data on real price index into logarithmic returns by the following method: $R_{t}=\ln \left(P_{t} / P_{t-1}\right) * 100$, where $P_{t}$ represents the real stock price index. There are 324 monthly observations on real stock returns and industrial production available over the period from January 1977 to December 2003 for Taiwan, 216 monthly observations from January 1986 to April 2003 for Japan, 196 monthly observations from January 1987 to April 2003 for Korea, and finally, 135 monthly observations from January 1987 to March 1998 for Malaysia.

The data for both of the empirical variables are seasonally adjusted according to the method suggested by Davidson et al. (1978). Following the conventional time series analysis approach, the ADF (Augmented Dickey and Fuller (1981)) test, PP (Phillips and Perron (1988)) test, and KPSS (Kwiatkowski, et al. (1992)) test are employed as a first step to examine the hypothesis of a unit root among the variables. If a unit root exists in each variable, Johansen (1995) cointegration test is applied to test for cointegration in a bivariate framework. The study then proceeds to examine the lag structure in order to obtain the optimal lag length for the unit root test. In the case of the ADF unit root test, the Akaike (1973) Information Criterion (AIC) technique is employed. The optimal lag lengths of PP and KPSS unit root test are based on Bartlett test (for greater details, see Newey and West (1994)). The resulting unit root tests indicate that the underlying series are stationary by rejecting the null hypothesis of the existence of a unit root among the variables; however, the series for real stock return for Japan and Malaysia are not stationary under the ADF unit root test at the $10 \%$ level of significance.

\section{Empirical Model}

In order to explore the lead-lag relationship between stock returns and output growth, the bivariate Granger causality via a VAR methodology is specified as follows:

$$
\begin{aligned}
& G P_{t}=\alpha_{0}+\sum_{i=1}^{k} \alpha_{1 i} G P_{t-i}+\sum_{i=1}^{k} \alpha_{2 i} R_{t-i}+\varepsilon_{1 t} \\
& R_{t}=\beta_{0}+\sum_{i=1}^{k} \beta_{1 i} G P_{t-i}+\sum_{i=1}^{k} \beta_{2 i} R_{t-i}+\varepsilon_{2 t}
\end{aligned}
$$

In the above framework, if the null hypothesis: 
$H_{0}: \alpha_{21}=\alpha_{22}=\ldots=\alpha_{2 k}=0$ is rejected, it implies that $R_{t} \rightarrow$ (Granger Cause) $G P_{t}$; thus, the rate of the stock returns is the leading indicator of output growth. Similarly, if the model rejects the null hypothesis: $H_{0}: \beta_{11}=\beta_{12}=\ldots=\beta_{1 k}=0$, it implies that $G P_{t} \rightarrow R_{t}$; thus, output growth is the leading indicator of stock returns. However, Equation (1) represents the linear bivariate VAR model, which is often used in previous studies. Since the objective of this paper is to investigate the potential existence of a nonlinear relationship between stock returns and output growth, this study proceeds to specify the threshold model to explore the asymmetric and cyclical behavior of the empirical variables.

The conventional threshold autoregressive (TAR) model is introduced by Tong (1978) and Tong and Lim (1980). The TAR model has the advantage of allowing the classification of the variable across regimes based on an estimate of the time series behavior that is consistent with reaching the threshold that separates the regimes. Consider a simple two-regime TAR model:

$y_{t}= \begin{cases}f_{01}+f_{11} y_{t-1}+u_{t} & \text { if } y_{t-1} \leq \gamma, \\ f_{02}+f_{12} y_{t-1}+u_{t} & \text { if } y_{t-1}>\gamma,\end{cases}$

where $y_{t}$ is the dependent variable, and $y_{t-1}$ is the threshold variable. $u_{t}$ is the error term, and $\gamma$ is the threshold value. The two-regime TAR model shows that when the threshold variable is smaller than the threshold value, the regression equation is equation (2); when the threshold variable is greater than the threshold value, the regression equation is equation (3). Specifying dummy variable as $I_{t}(\gamma)=\left\{q_{t} \leq \gamma\right\}$ and $\{\bullet\}$ as the indicator function when $q_{t} \leq \gamma, \mathrm{I}=1$, or $\mathrm{I}=0$. Combining equations (2) and (3) into the VAR representation of equation (1) yields the threshold vector autoregressive (TVAR) model:

$$
\begin{aligned}
& G P_{t}=\left(\alpha_{10}+\sum_{i=1}^{k} \alpha_{1 i}^{1} G P_{t-i}+\sum_{i=1}^{k} \alpha_{2 i}^{1} R_{t-i}\right)\left(1-I\left[q_{t}>\gamma\right]\right) \\
& +\left(\alpha_{20}+\sum_{i=1}^{k} \alpha_{1 i}^{2} G P_{t-i}+\sum_{i=1}^{k} \alpha_{2 i}^{2} R_{t-i}\right)\left(I\left[q_{t}>\gamma\right]\right)+\varepsilon_{1 t}^{*} \\
& R_{t}=\left(\beta_{10}+\sum_{i=1}^{k} \beta_{1 i}^{1} G P_{t-i}+\sum_{i=1}^{k} \beta_{2 i}^{1} R_{t-i}\right)\left(1-I\left[q_{t}>\gamma\right]\right) \\
& \left(\beta_{20}+\sum_{i=1}^{k} \beta_{1 i}^{2} G P_{t-i}+\sum_{i=1}^{k} \beta_{2 i}^{2} R_{t-i}\right)\left(I\left[q_{t}>\gamma\right]\right)+\varepsilon_{2 t}^{*}
\end{aligned}
$$

In equation (4), $q_{t}$ is the latent threshold variable. The lag term of the stock returns $R_{t-i}, i=1,2 \ldots k$ serves as the threshold variable given that the aim of this study is to investigate the influence of the stock market disturbance on output growth. When $R_{t-i} \geq \gamma$, it implies that the stock returns are higher than the threshold value, which is designated as the "good news regime". On the other hand, when $R_{t-i}<\gamma$, it implies that the stock returns are lower than the threshold value, which is designated as the "bad news regime."

Before applying the TVAR model such as (4), we need to test for the threshold effects. In this case, it is analogous to test the null hypothesis of the linear VAR model against the alternative hypothesis of the nonlinear TVAR model such as (4). However, the conventional methods of hypothesis testing cannot be applied because of the difficulty with the threshold parameter $\gamma$ being unidentified under the null hypothesis. In this case, the underlying distribution of a large sample is not Chi-square distribution. Hansen (1996) proposes a solution for this particular problem and suggests that relevant tests should be conducted by transforming the large sample distribution function of the statistics through the use of the bootstrap procedure to obtain the asymptotic $p$-value of the large sample. Once the null hypothesis is established, the sampling distribution of the $p$-value statistics is uniformly distributed. This study employs the supremum LM statistics proposed by Hansen (1996) to test the null hypothesis that the threshold variable is unidentified. Assuming the threshold variable is $R_{t-i} \in\left[\gamma_{L}, \gamma_{U}\right], i=1,2 \ldots k$, and the statistics is:

$\operatorname{Sup} L M=\sup _{L M\left(R_{t-i}\right)}$

$\gamma_{L} \leq R_{t-i} \leq \gamma_{U}$

As the asymptotic distribution of the statistics is unknown, the test statistics are computed through the simulation method. Refer to Hansen (1996) for an in-depth discussion of the method.

\section{Empirical Results and Conclusion}

The non-linear link between stock returns and output growth has been the subject of considerable interest and debate. While many published studies in recent years covered industrialized countries, a small number examined developing countries. The purpose of this study is to employ the newly developed threshold vector autoregressive methodology to investigate the non-linear relationship between industrial production growth rate and stock returns in Taiwan, Malaysia, Japan, and Korea.

The empirical results of this study indicate that there is an asymmetric relationship between stock returns and industrial production growth rate in the four East Asian countries. In Taiwan and Malaysia, when the stock returns are low (bad news regime), the rate of stock returns is a leading indicator of output growth. However, when the stock returns are high (good news regime), there is no correlation between the two. In the case of Japan and Korea, regardless of the stock returns regimes, the rate of stock returns is a leading indicator of output growth. The findings from the generalized impulse response 
function of the VAR model reveal that each country's stock market disturbance has a greater impulse effect on output growth under bad news regime than under good news regime.

\section{References}

[1] H. Akaike, "Information Theory and an Extension of the Maximum Likelihood Principle," In Petrov, B.N., \& Caski, F. (Eds.), $2^{\text {nd }}$ International Symposium on Information Theory, Budapest: Akademia Kiado, 1973.

[2] R. Barro, "The Stock Market and Investment," Review of Financial Studies, 3, pp.115-131, 1990.

[3] A. Bhide, "The Hidden Costs of Stock Market Liquidity," Journal of Financial Economics, 34 (1), pp. 1-51, 1993.

[4] M. Binswanger, "Stock Returns and Real Activity: Is There Still a Connection?" Applied Financial Economics, 10 (4), pp. 379-387, 2000.

[5] F. Canova, and G. Nicolo, "Stock Returns and Real Activity: A Structural Approach," European Economic Review, 39, pp. 981-1015, 1995.

[6] J. Choi, S. Hauser, and K. Kopecky, "Does the Stock Market Predict Real Activity? Time Series Evidence from the G-7 Countries," Journal of Bank and Finance, 23, pp. 1771-1792, 1999.

[7] J.E.H. Davidson, D.F. Hendry, F. Srba, and S. Yeo, "Econometric Modeling of the Aggregate Time-Series Relationship Between Consumers' Expenditure and Income in the United Kingdom," Economic Journal, 88, pp. 661-692, 1978.

[8] D. Dickey, and W.A. Fuller, "Likelihood Ratio Statistics for Autoregressive Time Series with a Unit Root," Econometrica, 49, pp. 1057-1072, 1981.

[9] D.L. Dolian, and D.A. Louton, "Business Cycle Asymmetry and the Stock Market," The Quarterly Review of Economic and Finance, 35, pp. 451-465, 1995.

[10]D.L. Domian, and D.A. Louton, "A Threshold Autoregressive Analysis of Stock Returns and Real Economic Activity," International Review of Economics and Finance, 6, pp. 167-179, 1997.

[11]S.C. Doong, "Stock Returns and Real Activity: Empirical Evidence from Asian Emerging Countries,"NSC report, NSC89-2416-H-035-023, 2001.

[12]E. Fama, "Stock Returns, Real Activity, Inflation and Money," American Economic Review, 71, pp. 545-564, 1981.

[13]E. Fama, "Stock Returns, Expected Returns, and Real Activity," Journal of Finance, 45, pp. 1089-1108, 1990.

[14]R. Filer, J. Hanousek, and N. Campos, "Do Stock Markets Promote Economy Growth?" Working Paper 267, 1999.
[15]B.E. Hansen, "Inference When A Nuisance Parameter Is Not Identified Under the Null Hypothesis," Econometrica, 64, pp. 413-430, 1996.

[16]Z. Hu, "The Yield Curve and Real Activity," Staff Papers (International Monetary Fund: Washington), 40 (4), pp. 781-806, 1993.

[17]S. Johansen, "Likelihood-Based Inference in Cointegrated Vector Autoregressive Models," Oxford University Press, 1995.

[18]D. Kwiatkowski, P.C.B. Phillips, P. Schmidt, and Y. Shin, "Testing the Null Hypothesis of Stationary Against the Alternative of a Unit Root: How Sure Are We That Economic Time Series Have a Unit Root?" Journal of Econometrics, 54, pp. 159-178, 1992.

[19]R. Levine, and S. Zervos, "Stock Market Development and Long-Run Growth," The World Bank Economic Review, 10 (2), pp. 323-339, 1996.

[20]P. Mauro, "Stock Markets and Growth: A Brief Caveat on Precautionary Saving," Economic Letters, 47, pp. 111-116, 1995.

[21]P. Mauro, "Stock Returns and Output Growth in Emerging and Advanced Economics," Journal of Development Economics, 71, pp. 129-153, 2003.

[22]R. Morck, A. Shleifer, and R.W. Vishny, "The Stock Market and Investment: Is the Market a Sideshow?" Brookings Papers on Economic Activity, 0 (2), pp. 157-202, 1990.

[23] M. Mullins, and S. Wadhwani, "The Effect of the Stock Market on Investment: A Comparative Study," European Economic Review, 33 (5), pp. 939-961, 1989.

[24]W. Newey, and K. West, "Automatic Lag Selection in Covariance Matrix Estimation," Review of Economic Studies, 61, pp. 631-653, 1994.

[25]M.Obstfeld,"Risk-Taking, Global Diversification, and Growth," American Economic Review, 84 (5), pp. 1310-1329, 1994.

[26]P.C.B. Phillips, and P. Perron, "Testing for a Unit Root," Biometrica, 75, pp. 1361-1401, 1988.

[27]N. Sarantis, "Nonlinearities, Cyclical Behavior and Predictability in Stock Markets: International Evidence," International Journal of Forecasting, 17, pp. 459-482, 2001.

[28] G. Schwert, "Stock Returns and Real Economic Activity: A Century of Evidence," Journal of Finance, 45, pp. 1237-1257, 1990.

[29]D. Sichel, "Business Cycle Asymmetry: A Deeper Look," Economic Inquiry, pp. 224-236, 1993.

[30]J.H. Stock, and M.W. Watson, "Business Cycle Properties of Selected U.S. Economic Time Series," NBER Working Paper 3376, 1990.

[31]J.H. Stock, and M.W. Watson, "Business Cycle Fluctuations in U.S. Macroeconomic Time Series," NBER Working Paper 6528, 1998. 
[32]M. Tamin, "Business Cycle Indicators for Malaysia," Tokyo: Institute of Developing Economies, pp. 45-157, 1988.

[33]H. Tong, "On a Threshold Model," in C.H. Chen (ed.) Pattern Recognition and Signal Processing, Amsterdan: Sijthoff \& Noordhoff, pp. 101-141, 1978.

[34]H. Tong, and K.S. Lim, "Threshold Autoregressions, Limit Cycles, and Data," Journal of the Royal Statistical Society, B42, pp. 245-292, 1980.

[35]B. Wahlroos, and T. Berglund, "Stock Returns, Inflationary Expectations, and Real Activity," Journal of Banking and Finance, 10, pp. 377-389, 1986. 